\title{
World Ophthalmology Congress, São Paulo, 2006
}

\author{
Rubens Belfort Jr.
}

Finalmente, depois de muito trabalho desenvolvido, por mais de 70 oftalmologistas que constituíram diferentes comissões, o Congresso Mundial de Oftalmologia que reúne o Congresso Internacional de Oftalmologia, o Congresso Pan-americano de Oftalmologia e o Congresso Brasileiro de Prevenção de Cegueira estarão se realizando daqui a dois meses.

Iniciamos este trabalho em 1998 quando o Paiva Gonçalves e eu organizamos no Rio de Janeiro o Congresso Pan-americano de Oftalmologia e com a ajuda e prestígio de Werther Duque Estrada e meu pai, Rubens Belfort Mattos, conseguimos trazer o Conselho Internacional de Oftalmologia para o Pré-Congresso no Rio de Janeiro. Na época a liderança mundial da oftalmologia percebeu então que o Brasil poderia, no futuro, ter condições de organizar com sucesso, um Congresso desta envergadura. Nossa Oftalmologia teve de ser aprovada nas várias etapas de seleção, até que finalmente, em Amsterdã em 1998 fomos oficialmente apontados como sede para 2006.

Somente conseguimos trazer e preparar este Congresso com apoio e força do CBO através dos seus Presidentes, Diretorias e Comissões nesses anos todos, bem como de seus excelentes funcionários.

O Conselho Brasileiro de Oftalmologia é motivo de orgulho para todos nós que devemos muito aos diferentes presidentes e suas gestões. Este me parece o momento adequado para lembrar, desde 1998, Geraldo Vicente de Almeida; Marcos Ávila; Suel Abujamra; Elisabeto Ribeiro Gonçalves e Harley E. A. Bicas. Também, devemos agradecer o apoio constante da nossa coirmã a Academia Americana de Oftalmologia e da Associação Pan-americana de Oftalmologia que sempre nos apoiaram nas diferentes fases da organização.

Foram dois anos de preparo intenso nesta reta final. Cerca de 200 mil mensagens eletrônicas. Uma enorme responsabilidade para todos nós, com inúmeros problemas sociais que temos e a preocupação, inclusive, com a segurança dos oito mil oftalmologistas mais os acompanhantes e expositores em um total provável de mais de 10 mil pessoas.
Teremos mais de quatro mil Temas-Livres aprovados, dos quais cerca de 5\% serão apresentados oralmente e nas áreas de maior recebimento de resumos (Retina, Glaucoma, Catarata, Uveíte, Refrativa e Prevenção de Cegueira). A Exposição Comercial terá de área construída, mais de $5.000 \mathrm{~m}^{2}$ ocupando um pavilhão de $20.000 \mathrm{~m}^{2}$, um recorde em toda a América Latina.

O objetivo desse Editorial é agradecer a todos que estão fazendo desse Congresso um evento Mundial que reforçará, esperamos, mais ainda o Brasil na Oftalmologia Internacional. Nossa competência oftalmológica é atualmente comprovada por todos. Nas 26 áreas da nossa especialidade tivemos sempre um Coordenador Brasileiro, de primeiro mundo, colaborando com a elaboração da programação científica.

Outro motivo desse Editorial é reforçar o convite para que cada Oftalmologista Brasileiro nos ajude a receber e lidar com os cerca de três mil convidados estrangeiros que estarão entre nós. Vamos precisar da ajuda de todos em todos os aspectos e este é um Congresso onde cada membro do Conselho Brasileiro de Oftalmologia é anfitrião e se sentirá orgulhoso por sua realização. Mantenha-se informado durante os próximos meses consultando periodicamente a Web site do Congresso www.ophthalmology2006.com.bre Bem-Vindos.

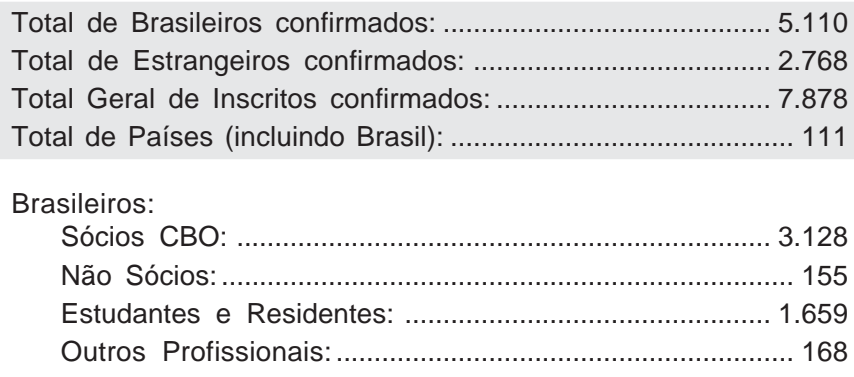

Total Estimado de Público Presente: ................................. 12.400 